\title{
MANAJEMEN DANA WAKAF TUNAI UNTUK PENGEMBANGAN LEMBAGA PENDIDIKAN ISLAM (Studi pada BMH Cabang Malang)
}

\author{
Ahmad Djalaludin \\ Maisyaroh \\ Fakultas Ekonomi Universitas Islam Negeri Maulana Malik Ibrahim Malang \\ Jl. Gajayana No. 50 Malang \\ jalal_uinmaliki@yahoo.com
}

Abstrak

Researcher was interested in conducting research in the Baitul Maal Hidayatullah Branch Malang with the aim to identify management of funds cash waqaf in these institutions and the general problem and the steps taken by BMH Branch Malang in overcoming these problems. This research is a qualitative with descriptive approach. The techniques used in data collection methods are observation, interview and documentation. The survey revealed that the funds cash waqaf collected by the BMH branch Malang targeted specifically for the education program for the development of Islamic educational institutions Ar-Rohmah for girls which is located in Dau Malang. The forms of development such as land acquisition in the vicinity/area of that institution. The main constraint in this management of cash fund of wakaf is the human resources/employees who are less optimal in performing his duties and it is difficult to be taken to develop the organization. To overcome this, the BMH branch Malang creates training initiatives in order to motivate their employees.

Kata Kunci: Wakaf Tunai, Lembaga Pendidikan Islam, Manajemen Dana

Anggaran pendidikan yang disediakan oleh APBN sampai saat ini masih jauh dari ideal. Dibanding dengan anggaran pendidikan negara-negara maju yang mencapai 7\% dari Gross Domestic Product (GDP), negara-negara berkembang sangat 
terpaut jauh, yaitu 2,5\%. Adapun Indonesia, anggaran yang disediakan hanya berkisar 1 persen dari GDP (http://blog.re.or.id diakses tanggal 16 Februari 2010 jam 11.35). Kenyataan ini menunjukkan bahwa pemerintah belum serius menggarap sektor pendidikan. Ada banyak sebab yang mengakibatkan hal tersebut, diantaranya adalah rendahnya kesadaran para pengambil kebijakan negeri ini terhadap aspek pendidikan atau karena minimnya ketersediaan anggaran. Akibatnya mutu pendidikan di Indonesia terhitung masih rendah dan SDM yang dihasilkan memiliki daya saing yang rendah.

Melihat keterbatasan ini muncul pertanyaan apakah ada konsep fund for education yang ditawarkan Islam? Untuk menjawab pertanyaan ini perlu melihat bagaimana lembaga-lembaga pendidikan Islam klasik mampu berkiprah dan survive. Bagaimana lembaga-lembaga pendidikan Islam terkemuka seperti Al-Azhar University di Kairo, Zaituniyah University di Tunis, dan ribuan madaris Imam Lisesi di Turki mampu bertahan berabad-abad lamanya, dan memberikan beasiswa kepada jutaan mahasiswa selama lebih 1000 tahun dari seluruh penjuru dunia? Lembagalembaga pendidikan itu bukanlah lembaga pendidikan yang fully profit oriented. Mereka adalah lembaga pendidikan yang lebih bercorak sosial. Apakah mungkin pendanaannya hanya mengandalkan sedekah dan infak masyarakat setempat, sementara mereka harus membiayai operasionalnya sendiri, membangun sarana belajar mengajar tambahan, dan memberikan beasiswa kepada jutaan mahasiswa? Salah satu jawabannya adalah mereka telah berhasil mengembangkan cash waqf (wakaf tunai) sebagai sumber dana untuk pengembangan dan operasional pendidikan (Tim Dirjen Bimas Islam: 2007:73).

Salah satu contoh lembaga pendidikan di Indonesia yang mampu mengelola wakafnya secara profesional dan produktif adalah Pondok Modern Darussalam Gontor (PMDG). Pondok Modern Gontor Darussalam Gontor (PMDG) ditopang oleh sekitar 320 hektar lahan wakaf, 212 hektar di antaranya adalah sawah produktif. Dari sini Pondok Gontor memperoleh hasil panen senilai Rp 726 juta tiap dua musim panen (data 2003). Selain dari sawah padi, Pondok Modern Gontor (PMDG) juga memperoleh pendapatan dari kebun cengkeh dan kegiatan niaga lain di lingkungannya, meski relatif lebih kecil. Dengan dukungan dana wakaf ini, Pondok Gontor mampu menyediakan jasa pendidikan bermutu bagi sekitar 35 ribu siswa dengan biaya yang relatif murah. Sebagian besar benda wakaf Gontor dikelola secara produktif dengan usaha pertanian, perkebunan, percetakan, retail, apotik, wartel, penggilingan padi, toserba, dan lain-lain yang hasilnya untuk pengelolaan dan peningkatan kualitas pondok serta untuk kepentingan kesejahteraan masyarakat sekitar. (http://www.kompasiana.com/posts/index/ opinion diakses pada tanggal 19 Mei 2010 pukul 06.49 wib).

Di Indonesia, masih banyak harta wakaf yang dikelola secara konsumtif dan tradisional. Sehingga peranannya sebagai katalisator bagi problem sosial dan ekonomi umat tidak maksimal. Sesungguhnya ada beberapa permasalahan yang 
menyebabkan potensi wakaf di Indonesia belum produktif. Salah satu permasalahan ini terletak di tangan nazhir selaku pemegang amanah dari waqif (orang yang berwakaf) untuk mengelola dan mengembangkan harta wakaf.

Harta wakaf tunai harus dikelola dan diberdayakan dengan manajemen yang baik dan modern. Pemberdayaan harta wakaf tunai ini mutlak diperlukan dalam rangka menjalin kekuatan ekonomi umat demi meningkatkan kesejahteraan masyarakat banyak. Selain itu, untuk mengelola dan mengembangkan wakaf tunai dengan baik, dibutuhkan sumber daya insani yang amanah, profesional, berwawasan ekonomi, tekun dan penuh komitmen yang kuat.

Dalam Peraturan Pemerintah No. 42 Tahun 2006 pasal 48, disebutkan bahwa wakif dapat mewakafkan benda bergerak berupa uang melalui Lembaga Keuangan Syariah yang ditunjuk oleh menteri. Peraturan tersebut sepertinya memberikan arahan kepada kita bahwa kelak pengelolaan wakaf tunai lebih banyak diserahkan kepada LKS, meskipun peraturan tersebut tidak menutup kemungkinan adanya lembaga selain LKS dipercaya oleh wakif untuk mengelola wakaf tunai.

Arahan dari aturan ini tidak berlebihan, tapi justru sangat tepat mengingat struktur LKS ini sudah relatif well established dan mempunyai sofistikasi dalam pengelolaan aset/keuangan. Seperti perbankan syariah misalnya, sebagai manager investasi lembaga keuangan ini dalam operasionalnya selalu disupervisi bukan hanya oleh otoritas moneter tetapi juga oleh Dewan Pengawas Syariah (DPS) untuk memastikan lembaga ini patuh dengan prinsip kehati-hatian dan compliance dengan prinsip syariah, sehingga default risk dan syariah risk yang melekat pada lembaga ini relatif bisa dikendalikan. Hal yang sama juga dimiliki oleh manager investasi yang lain di bidang keuangan dan perbankan seperti reksadana. Oleh karenanya, LKS mempunyai potensi yang besar untuk promote menjadi pengelola aset wakaf tunai. (Wadjdy dan Mursyid, 2007:171).

Melihat hal ini, penulis tertarik untuk melakukan penelitian terkait dengan manajemen dana wakaf tunai pada lembaga sosial yang dikelola umat Islam. Dan pada penelitian ini, penulis akan melakukan penelitian di Baitul Maal Hidayatullah Cabang Malang.

Baitul Maal Hidayatullah Cabang Malang adalah lembaga sosial yang bergerak di bidang pengumpulan dan pengelolaan ZISWAF (zakat, infaq, shadaqah dan wakaf). Pada mulanya, Baitul Maal Hidayatullah Cabang Malang adalah bagian dari organisasi sosial Hidayatullah. Seiring meningkatnya kepercayaan masyarakat terhadap organisasi sosial ini, maka pada tanggal 24 April 2002 Baitul Maal Hidayatullah Cabang Malang resmi menjadi lembaga yang dikelola secara otonom, baik dari sisi manajemen maupun keuangannya, untuk lebih meningkatkan profesionalitas serta totalitas kinerja segenap pengurus.

Untuk dapat merealisasikan tujuannya, BMH Cabang Malang memiliki beberapa program yang dicanangkan meliputi program bidang dakwah, pendidikan, sosial, dan ekonomi. Dalam program pendidikan, BMH Cabang Malang memiliki beberapa 
layanan/program bagi para donatur yang ingin menyumbangkan dananya diantaranya adalah layanan/program wakaf tunai. Dalam program ini, dana yang telah dihimpun disalurkan khusus untuk pengembangan lembaga pendidikan Islam. Salah satu keunggulan yang dimiliki oleh BMH Cabang Malang melalui program ini adalah meskipun BMH Malang adalah cabang akan tetapi mereka mampu menerbitkan sertifikat wakaf tunai secara mandiri.

Melihat permasalahan di atas penulis tertarik untuk memahami lebih dalam tentang "Manajemen Dana Wakaf Tunai untuk Pengembangan Lembaga Pendidikan Islam (Studi pada Baitul Maal Hidayatullah (BMH) Cabang Malang)".

Melalui penelitian ini diharapkan peneliti memahami bagaimana manajemen dana wakaf tunai yang dilaksanakan oleh Lembaga Amil Zakat Baitul Maal Hidayatullah Cabang Malang untuk Pengembangan Lembaga Pendidikan Islam, problematika yang dihadapi, serta langkah-langkah yang ditempuh untuk mengatasi berbagai problematika tersebut.

\section{METODE PENELITIAN}

Penelitian ini dilakukan di Lembaga Amil Zakat Baitul Maal Hidayatullah Cabang Malang yang bertempat di Jl. Sidomakmur 15, Sengkaling Dau Malang.

Jenis penelitian yang digunakan adalah penelitian kualitatif dengan pendekatan deskriptif. Penelitian kualitatif merupakan penelitian yang bermaksud untuk memahami fenomena tentang apa yang dialami oleh subjek penelitian misalnya perilaku, persepsi, motivasi, tindakan dan lain-lain, secara holistik, dan dengan cara deskripsi dalam bentuk kata-kata dan bahasa, pada suatu konteks khusus yang alamiah dan dapat memanfaatkan berbagai metode alamiah (Moleong, 2006:6).

Adapun sumber data yang digunakan dalam penelitian ini dibagi menjadi dua yaitu, data primer dan data sekunder. Data primer adalah data yang diperoleh atau dikumpulkan langsung di lapangan oleh orang yang melakukan penelitian atau yang bersangkutan yang memerlukannya (Hasan, 2002:82). Data ini berupa hasil wawancara dengan informan yang dianggap relevan untuk diambil data darinya. Dalam hal ini informan yang dimaksud adalah orang-orang yang ada dalam struktur kepengurusan BMH Cabang Malang. Data sekunder adalah data yang diperoleh peneliti secara tidak langsung mengenai manajemen dana wakaf tunai di BMH Cabang Malang. Data berupa profil LAZNAS Baitul Maal Hidayatullah Cabang Malang, laporan keuangan, data tentang aset wakaf tunai, sertifikat wakaf tunai, data jumlah wakif, dan lain-lain. Yang biasanya menggunakan data dokumentasi seperti majalah, internet, buku-buku yang mendukung penelitian ini dan sebagainya.

Untuk mengumpulkan data dan keterangan yang diperlukan, maka penulis menggunakan teknik pengumpulan data meliputi: observasi, wawancara, dan dokumentasi. Observasi mengoptimalkan kemampuan peneliti dari segi motif, 
kepercayaan, perhatian, kebiasaan dan sebagainya. (Moleong, 2006:175) Dalam hal ini, penulis akan langsung terjun mendatangi lokasi penelitian yaitu BMH Cabang Malang dan lokasi pemanfaatan dana wakaf tunai yang dikelola BMH Cabang Malang.

Teknik wawancara yang digunakan pada penelitian ini adalah teknik wawancara tidak terstruktur. Wawancara tak terstruktur sering juga disebut wawancara mendalam, wawancara intensif, wawancara kualitatif, dan wawancara terbuka (openended interview) (Mulyana, 2003:180). Dalam penelitian ini, penulis melakukan wawancara dengan beberapa informan yang paling mengetahui tentang pengelolaan dana wakaf tunai dan mekanisme kerja di BMH Cabang Malang yaitu: Bapak Abdullah Warsito, S. Hum selaku branch manager, Bapak Abu Fadhillah, S. Psi selaku manager keuangan, Bapak Sudarman selaku manager fundrising, Bapak Humam Hidayat, S. Hum selaku manager pendayagunaan dana, Bapak Imron Mahmudi selaku pegawai bidang administrasi.

Dokumentasi adalah teknik pengumpulan data yang tidak langsung ditujukan pada subyek penelitian, namun melalui dokumen. Dokumen yang digunakan dapat berupa laporan keuangan, profil, struktur organisasi, job discription Baitul Maal Hidayatullah Cabang Malang dan dokumen lainnya.

Analisis data dalam penelitian ini adalah analisis data kualitatif, dimana analisis datanya dilakukan dengan cara non statistik, yaitu penelitian yang dilakukan dengan menggambarkan data yang diperoleh dengan kata-kata atau kalimat yang dipisahkan dalam kategori-kategori untuk memperoleh kesimpulan. Miles dan Huberman (1984) dalam Sugiyono (2008:91), mengemukakan bahwa aktivitas dalam analisis data kualitatif dilakukan secara interaktif dan berlangsung secara terus-menerus sampai tuntas, sehingga datanya sudah jenuh. Aktivitas dalam analisis data, yaitu data reduction, data display, dan conclucion drawing/verification.

\section{PEMBAHASAN HASIL PENELITIAN}

\section{Sejarah Baitul Maal Hidayatullah Cabang Malang}

Pada mulanya, Baitul Maal Hidayatullah Cabang Malang yang saat ini berlokasi di SidoMakmur 15 Sengkaling Dau Malang adalah bagian dari organisasi sosial Hidayatullah. Seiring meningkatnya kepercayaan masyarakat terhadap organisasi sosial ini, maka diputuskan bahwa lembaga tersebut berdiri secara otonom, baik dari sisi manajemen maupun keuangannya, untuk lebih meningkatkan profesionalitas serta totalitas kinerja segenap pengurus.

Akhirnya pada tanggal 24 April 2002, lembaga amil zakat Baitul Maal Hidayatullah Cabang Malang resmi berdiri berdasarkan SK notaris untuk wilayah Malang Nomor 191 Tahun 2002, dan memutuskan Zainal Musthofa sebagai direktur yayasan pertama. Namun, dipertengahan kepengurusan, tepatnya pada tanggal 31 Maret 2005, terjadi perubahan anggaran dasar yayasan Baitul Maal Hidayatullah 
berdasarkan SK notaris Nomor 4 Tahun 2005, yang menetapkan Abdullah Warsito, S. Hum sebagai direktur yayasan Baitul Maal Hidayatullah Cabang Malang yang baru. Dalam kiprahnya BMH Cabang Malang menghimpun dana dari masyarakat (pemerintah, BUMN, swasta, dll) berupa zakat, infaq, waqaf, hibah dll. Selanjutnya BMH menyalurkan kepada yang berhak menerimanya sesuai dengan programprogram yang dicanangkan.

\section{Penghimpunan Dana Wakaf Tunai}

Wakaf tunai adalah program yang relatif masih baru di Indonesia, namun berpotensi besar dalam mewujudkan kesejahteraan sosial. Karena itu diperlukan upaya yang masif dan intensif dalam sosialisasi agar lebih cepat diterima oleh masyarakat. Peran pemerintah dan nazhir (pengelola) baik lembaga maupun perorangan menjadi sangat penting demi suksesnya program ini. Tidak terkecuali lembaga amil zakat Baitul Maal Hidayatullah Cabang Malang yang bergerak di bidang penghimpunan dan penyaluran ZISWAF dan telah memperkenalkan program wakaf tunai sejak tahun 2005.

BMH Cabang Malang telah melakukan langkah-langkah strategis dengan menggunakan beberapa media untuk memperkenalkan produk-produknya termasuk wakaf tunai, antara lain: brosur, majalah, promosi di radio, membuka gerai, dan door to door. Menurut penuturan Bapak Sudarman, manager fundrising BMH Cabang Malang, langkah terakhir ini dinilai sangat strategis melihat donatur yang dihasilkan lebih banyak dibandingkan langkah-langkah lainnya.

BMH juga menyediakan beberapa alternatif layanan bagi calon donatur yang ingin menyumbangkan dananya baik itu berupa infaq, zakat, shadaqah maupun wakaf. Pertama, calon donatur bisa langsung menghubungi pihak BMH kemudian petugas akan mendatangi kediaman calon donatur untuk mengambilnya. Kedua, calon donatur bisa datang langsung ke BMH Cabang Malang yang terletak di jalan Sido Makmur No. 15 Sengkaling Dau Malang dengan terlebih dahulu mengisi blanko aplikasi donatur yang telah disediakan oleh lembaga. Di dalam blanko tersebut terdapat beberapa pilihan apakah dana akan disalurkan berupa infaq, zakat atau yang lainnya sesuai dengan keinginan para calon donatur. Selain blanko aplikasi donatur, pihak lembaga juga menyediakan tanda terima untuk donatur.

Alternatif ketiga bagi calon donatur yang ingin menyumbangkan dananya ke BMH Cabang Malang adalah melalui transfer bank ke rekening a/n BMH Cabang Malang. Untuk program wakaf tunai, wakif (orang yang mewakafkan hartanya) berhak mendapatkan sertifikat wakaf tunai sebagai bukti bahwa mereka telah mewakafkan hartanya. Akan tetapi ada sebagian wakif yang menolak untuk dicantumkan namanya sehingga mereka memilih untuk tidak mengambil sertifikat tersebut.

Di lembaga amil zakat BMH Cabang Malang, yang bertugas menghimpun dana adalah tim yang berada di bawah devisi fundrising. Pada awalnya devisi 
fundrising di BMH Cabang Malang dipimpin oleh Bapak Sudarman dan beranggotakan 3 orang. Tahun ini devisi fundrising dibagi menjadi 2 bagian yaitu bagian penarikan dan bagian pengembangan.

Bagian penarikan bertugas mengumpulkan/menarik dana dari para donatur yang telah rutin (tetap) menyumbangkan dananya ke BMH Cabang Malang. Selain mengumpulkan dana dari para donatur rutin, devisi ini juga bertugas mempertahankan agar donatur tidak menghentikan suntikan dananya ke BMH Cabang Malang. Devisi ini dikepalai oleh bapakAbu Fadhillah, S. Psi yang merangkap jabatan sebagai manager keuangan di lembaga yang sama dan dibantu oleh tim yang beranggotakan 4 orang.

Sedangkan tugas dari bagian pengembangan atau yang biasa mereka sebut dengan devisi Markom (Marketing Komunikasi) adalah terjun ke lapangan untuk mencari dan mengumpulkan dana dari para donatur baru. Devisi ini dikepalai oleh bapak Sudarman yang dibantu oleh tim yang beranggotakan 3 orang. Selain dari kedua devisi di atas, penghimpunan dana juga dilakukan oleh freelance (relawan) yang berasal dari instansi-instansi yang memiliki kerjasama dengan lembaga amil zakat BMH Cabang Malang seperti Universitas Brawijaya, Universitas Widyagama, Universitas Muhammadiyah Malang, dan lain-lain.

Manajemen penghimpunan dana yang dimiliki oleh BMH Cabang Malang sekarang memberikan kontribusi yang baik bagi perkembangan jumlah dana wakaf tunai dari tahun ke tahun berikutnya, hal ini dapat dilihat dari laporan keuangan lembaga tersebut.

Tabel 1. Jumlah Penerimaan Dana Wakaf Tunai BMH Cabang Malang Tahun 2006-2009

\begin{tabular}{clcl}
\hline No. & \multicolumn{1}{c}{ Sumber Dana } & Tahun & \multicolumn{1}{c}{ Nominal } \\
\hline 1. & Wakaf PPAS Putri & 2006 & Rp 47.595.000 \\
2. & Wakaf PPAS Putri Ramadhan & & Rp 103.125.000 \\
3. & Wakaf PPAS Putri & 2007 & $\operatorname{Rp~} 168.178 .818$ \\
4. & Wak af PPAS Putri & 2008 & $\operatorname{Rp~} 170.768 .000$ \\
& Wakaf PPAS Putri Ramadhan & \multirow{2}{*}{2009} & $\operatorname{Rp~333.056.000~}$ \\
\hline
\end{tabular}

Sumber: Laporan Keuangan BMH Cabang Malang tahun 2006-2009: data diolah

Dari tabel 1 diatas, bisa dilihat bahwa pada tahun 2006 dana yang berhasil dihimpun berjumlah Rp. 150.720.000,- (wakaf PPAS putri dan PPAS putri ramadhan) dan meningkat pada tahun 2007 menjadi Rp. 168.178.818,-. Hingga tahun 2009 jumlah dana yang berhasil dihimpun telah mencapai Rp. 333.606.000.

Dengan peningkatan sumber dana wakaf tunai yang berhasil dihimpun oleh lembaga amil zakat Baitul Maal Hidayatullah Cabang Malang selama kurun waktu 5 tahun terakhir ini, peneliti dapat menyatakan bahwa kinerja BMH Cabang Malang 
dalam melakukan penghimpunan dana sangat baik. Hal ini juga membuktikan bahwa BMH Cabang Malang telah mendapatkan kepercayaan dari masyarakat dan lembaga keuangan lainnya sebagai lembaga sosial yang mampu mengelola keuangan dengan baik dan sesuai dengan syariat Islam.

\section{Pola Pengelolaan Dana Wakaf Tunai}

Pengelolaan wakaf tunai di BMH Cabang Malang dilakukan secara semi profesional. Pihak BMH Cabang Malang sebagai nazhir masih mengelola harta wakafnya secara tradisional yakni untuk pembebasan lahan dalam rangka mengembangkan lembaga pendidikan Ar-Rohmah. Meskipun demikian para pengurus BMH Cabang Malang sudah mulai memahami untuk melakukan pengembangan harta wakaf lebih produktif. Hal ini diketahui dari hasil wawancara dengan bapak Abdullah Warsito pada tanggal 13 April 2010 pukul 13.10 wib.

\section{Pengelolaan Dana Wakaf Tunai untuk Pengembangan Lembaga Pendidikan Islam}

Pendistribusian dana di lembaga amil zakat BMH Cabang Malang dilakukan oleh devisi pendayagunaan. Devisi yang dipegang oleh bapak Humam Hidayat S.Hum yang sampai saat ini belum memiliki tim seperti devisi-devisi lainnya.

Menurut keterangan dari bapak Humam Hidayat pada tanggal 24 Maret 2010, bahwa dana wakaf tunai ini termasuk dana khusus. Yang dimaksud dana khusus di sini adalah dana yang diberikan donatur yang terlebih dahulu telah diikrarkan/ diniatkan secara tertulis bahwa dana tersebut diperuntukkan untuk program yang diinginkan oleh donatur misalkan untuk wakaf tunai. Pihak BMH Cabang Malang sendiri tidak memberikan batasan-batasan tertentu kepada wakif dalam menyumbangkan dananya. Hanya dalam brosur yang mereka buat mencantumkan informasi bahwa BMH akan menyalurkan dana wakaf tunainya untuk membebaskan atau membeli lahan Ar-Rohmah seharga Rp. 200.000,-/M².

Dana wakaf tunai yang dihimpun oleh BMH Cabang Malang didistribusikan khusus untuk program pendidikan yaitu untuk pengembangan lembaga pendidikan Islam (LPI) Ar-rohmah Putri yang terletak di daerah Dau Malang. Sedangkan bentuk pengembangannya yaitu dengan membebaskan lahan di sekitar/area lembaga pendidikan tersebut. Pihak BMH cabang Malang sendiri hanya bertugas menyalurkan dana ini sedangkan pengelolaannya diserahkan pada yayasan LPI Ar-rohmah di bawah naungan pesantren Hidayatullah Cabang Malang. Luas lahan/tanah yang telah dibebaskan saat ini telah mencapai 1,5 hektar, sedangkan target pencapaian luas lahan yang ingin dibebaskan adalah 5 hektar. Lahan-lahan ini adalah milik masyarakat sekitar lembaga pendidikan Islam Ar-rohmah. 


\section{Problematika Pengelolaan Dana Wakaf Tunai di BMH Cabang Malang}

Dari hasil wawancara dengan beberapa manager di BMH Cabang Malang dapat diketahui ada beberapa problematika yang menjadi kendala dalam pengelolaan dana baik dari segi penghimpunan dana maupun pendistribusian dana.

\section{Penghimpunan Dana}

Dari penuturan bapak Sudarman selaku manager fundrising, beberapa kendala yang sering mereka alami antara lain: (1) Adanya donatur rutin yang tiba-tiba menghentikan sumbangan dananya tanpa pemberitahuan sebelumnya, (2) Adanya $\mathrm{SDM} /$ karyawan yang kurang optimal dalam menjalankan tugasnya dan sulit untuk diajak mengembangkan organisasi, (3) Kadangkala petugas BMH mendapatkan sambutan yang tidak baik dari pemilik rumah saat menawarkan program-programnya.

\section{Pendistribusian Dana}

Dalam hal mendistribusikan dana wakaf tunainya, secara khusus BMH Cabang Malang masih belum menemukan kendala yang berarti. Namun secara umum ada beberapa kendala yang sering mereka alami yaitu: (1) Laporan dari KPM3 yang tidak seragam baik dari laporan keuangan maupun laporan-laporan lainnya seperti laporan terselenggaranya program-program, laporan terkait dokumentasi-dokumentasi, maupun pelaporan bukti transaksi, dan (2) program tidak berjalan karena dana digunakan untuk biaya operasional (biaya diambil dari dana infaq). Khusus untuk program wakaf tunai, dana ini tidak diambil sedikitpun untuk biaya operasional. Dana yang dihimpun semuanya dialokasikan ke LPI Ar-Rohmah Putri secara utuh.

\section{Langkah-Langkah Solutif:}

\section{Penghimpunan Dana}

Untuk memastikan penyebab donatur yang tiba-tiba menghentikan donasi dananya, pihak/petugas mendatangi donatur tersebut dan menanyakan penyebab keputusan penghentian itu. Mayoritas para donatur menghentikan donasinya dengan alasan bahwa mereka sudah tidak menetap di wilayah Malang raya/pindah ke luar kota. Dari pernyataan para donatur tersebut pihak BMH akan memberikan pengarahan dan penjelasan kepada donatur tersebut jika berkenan menyumbangkan dananya kembali bisa melalui cabang BMH yang ada di kota tempat tinggal yang baru atau bisa juga di wilayah-wilayah yang ada cabang BMHnya yang tentunya dekat dengan kota tempat tinggal donator yang baru.

Untuk mengantisipasi menurunnya semangat dan adanya SDM/karyawan yang kurang optimal dalam menjalankan tugasnya dan sulit untuk diajak mengembangkan organisasi, pihak BMH membuat inisiatif mengadakan pelatihan guna memotivasi karyawannya. Contoh bentuk motivasi yang pernah dilakukan oleh BMH Cabang 
Malang adalah training tentang pentingnya manajemen, studi banding, pemberian kajian keislaman berkenaan dengan pengelolaan dana kebajikan ini, dan MABIT (Malam Bina Taqwa).

\section{Distribusi dana}

Format dan bentuk pelaporan yang diberikan oleh pihak KPM3 dari berbagai wilayah di Malang raya memang banyak yang belum seragam. Untuk mengatasi hal tersebut, pihak BMH Cabang Malang khususnya devisi pendayagunaan dana berencana menyeragamkan format dan sistem pelaporan dari KPM3 tiap-tiap wilayah. Hal ini untuk memudahkan devisi pendayagunaan dana dalam mengecek dana yang telah disalurkan oleh KPM3 (apakah dana tersebut digunakan sesuai dengan pengajuan awal oleh pihak KPM3) dan menganalisis dana yang akan diberikan kepada KPM3 (apakah pengajuan dana tersebut sudah sesuai dengan tujuan program). Penyeragaman ini juga dilakukan sebagai bentuk pengawasan BMH khususnya devisi pendayagunaan dana terhadap jalannya dana (pendistribusian dan pendayagunaan dana).

Untuk mengantisipasi berkurangnya dana disebabkan oleh pengeluaran biaya operasional yang begitu besar, pihak BMH khususnya devisi keuangan membuat strategi untuk meminimalisir pengeluaran dana operasional yang diambil dari dana infaq. Selain itu, untuk planning ke depan BMH Cabang Malang akan membuat program-program yang telah dirancang sebelumnya diarahkan untuk pemberdayaan yang lebih produktif. Sehingga hasil yang diperoleh lebih besar dan manfaaatnyapun juga semakin bertambah besar demi kesejahteraan umat, pegawai dan BMH sendiri.

\section{KESIMPULAN}

Lembaga amil zakat BMH Cabang Malang mengalokasikan dana wakaf tunainya khusus untuk pengembangan lembaga pendidikan Islam Ar-Rohmah Putri yang terletak di Dau Malang. Pemanfaatan dana tersebut berupa pembebasan lahan di sekitar/area lembaga pendidikan. Pengelolaan wakaf tunai di BMH Cabang Malang ini tergolong semi profesional. Pihak BMH Cabang Malang sebagai nazhir masih mengelola harta wakafnya secara tradisional yakni untuk pembebasan lahan dalam rangka pengembangan lembaga pendidikan Islam (LPI) Ar-Rohmah. Pihak BMH Cabang Malang hanya bertugas menghimpun sedangkan pengelolaannya diserahkan pada yayasan LPI Ar-rohmah di bawah naungan pesantren Hidayatullah Cabang Malang.

Beberapa problematika yang menjadi kendala dalam pengelolaan dana baik dari segi penghimpunan dana maupun pendistribusian dana di BMH cabang Malang diantaranya: (1) Adanya donatur rutin yang tiba-tiba menghentikan donasinya tanpa pemberitahuan sebelumnya, (2) Adanya SDM/karyawan yang kurang optimal dalam menjalankan tugasnya dan sulit untuk diajak mengembangkan organisasi, (3) Kadang 
petugas BMH mendapatkan sambutan yang tidak baik saat menawarkan programprogramnya, (4) Laporan dari KPM3 yang tidak seragam, (5) Program tidak berjalan karena dana digunakan untuk biaya operasional (biaya diambil dari dana infaq).

Sedangkan langkah-langkah yang ditempuh oleh BMH cabang Malang dalam mengatasi berbagai kendala di atas meliputi: (1) Untuk memastikan penyebab donatur yang tiba-tiba menghentikan donasinya, petugas mendatangi donatur guna menanyakan penyebab penghentian itu, (2) secara berkala $\mathrm{BMH}$ melakukan pembinaan bagi para karyawannya melalui beberapa kegiatan diantaranya: Training yang diadakan 1 bulan sekali untuk memotivasi karyawan, MABIT (Malam Bina Taqwa), studi banding, dan pembinaan terkait kajian keislaman, (3) Untuk mengantisipasi kejadian serupa terulang kembali, sebelum mendatangi kediaman para calon donatur/ masyarakat, pihak $\mathrm{BMH}$ berusaha mencari data dan informasi mengenai calon donaturnya tersebut dari sumber-sumber terpercaya. Berbekal dari data dan informasi yang didapat, petugas dapat menganalisis dan merencanakan strategi apa yang digunakan dalam penyampaian maksud dan tujuan mereka datang, (4) Untuk mengatasi ketidakseragaman laporan dari KPM3, pihak BMH cabang Malang khususnya devisi pendayagunaan dana berencana menyeragamkan format dan sistem pelaporan dari KPM3 tiap-tiap wilayah. Hal ini untuk memudahkan devisi pendayagunaan dana dalam mengecek dana yang telah disalurkan oleh KPM3 (apakah dana tersebut digunakan sesuai dengan pengajuan awal oleh pihak KPM3) dan menganalisis dana yang akan diberikan kepada KPM3 (apakah pengajuan dana tersebut sudah sesuai dengan tujuan program). Penyeragaman ini juga dilakukan sebagai bentuk pengawasan BMH khususnya devisi pendayagunaan dana terhadap jalannya dana (pendistribusian dan pendayagunaan dana), (5) Sedangkan untuk mengantisipasi habisnya dana disebabkan oleh pengeluaran biaya operasional yang begitu besar, pihak BMH khususnya devisi keuangan membuat strategi untuk meminimalisir pengeluaran dana operasional yang diambil dari dana infaq. Selain itu, untuk planning ke depan BMH cabang Malang akan membuat program-program yang telah dirancang sebelumnya diarahkan untuk pemberdayaan yang lebih produktif lagi.

\section{DAFTAR PUSTAKA}

Arif, N. 2010. Menciptakan Keberlangsungan Lembaga Pendidikan. http://www. kompasiana.com/welcome. 29 April 2010 , 2010. Memandirikan Lembaga Pendidikan dengan Wakaf.

http://www.kompasiana.com/posts/index/opinion. 13 April 2010.

Arikunto, S. 2002. Prosedur Penelitian Suatu Pendekatan Praktek. Edisi revisi V. Jakarta: Penerbit PT. Rineka Cipta.

Azwar, S. 1999. Metode Penelitian. Yogyakarta: Penerbit PT Pustaka Pelajar.

B. Miles, Matthew, dan A. Michael Huberman. 1992. Analisis Data Kualitatif. Jakarta: Penerbit UI Press. 
Djakfar, M. 2007. Etika Bisnis dalam perspektif Islam. Malang: Penerbit UIN Press.

Hafidhuddin, D., dan Hendri, T. 2003. Manajemen Syariah dalam Praktik. Jakarta: Penerbit Gema Insani Press.

Hani, H. 2001. Manajemen. Yogyakarta: Penerbit BPFE.

Hasan, I. 2002. Pokok-Pokok Materi Metodologi Penelitian dan Aplikasinya. Penerbit Ghalia Indonesia.

Hasibuan, Malayu, S.P. 2005. Manajemen; Dasar, Pengertian, dan Masalah. Jakarta: Penerbit PT Bumi Aksara.

Huda, N. 2009. Manajemen Pengelolaan Tanah Wakaf di Majelis Wakaf dan Zakat, Infaq, Shadaqah (ZIS) Pimpinan Daerah Muhammadiyah Kabupaten Malang. Skripsi. Malang: FE-UIN.

IA, Suparman. 2009. Manajemen Fundrising dalam Penghimpunan Harta Wakaf 2. www. bwi.orid.

Isfandiar, A.A. 2008. Tinjauan Fiqh Muamalat dan Hukum Nasional tentang Wakaf di Indonesia. Jurnal Ekonomi Islam, Vol. II (1):55.

Mahmudah, U. 2007. Manajemen Dana di Lembaga Zakat (Studi pada Lembaga Zakat Baitul Maal Hidayatullah Cabang Malang). Skripsi. Malang: FE-UIN.

Moleong, L.J. 2006. Metodologi Penelitian Kualitatif. Penerbit PT Remaja Rosdakarya, Bandung.

Mulyana, D. 2003. Metodologi Penelitian Kualitatif; Paradigma Baru Ilmu Komunikasi dan Ilmu Sosial Lainnya. Bandung: Penerbit PT Remaja Rosdakarya.

Qahaaf, M. 2005. Manajemen Wakaf Produktif. Jakarta: Penerbit Khalifa.

Rahman, A. 1995. Doktrin ekonomi Islam jilid II. Yogyakarta: Penerbit PT Dhana Bakti Prima Yasa.

Rahmat. 2009. Cash Waqf dan Anggaran Pendidikan Umat. http://blog.re.or.id

Setyawan, A.A. 2004. Wakaf Tunai dan Kesejahteraan Ummat. http://www. hidayatullah. com/opini.html

Sudarsono, H. 2003. Bank dan Lembaga Keuangan Syariah: Deskripsi dan Ilustrasi. Cetakan keempat. Yogyakarta: Penerbit EKONISIAUII.

Sugiono. 2008. Memahami Penelitian Kualitatif. Jakarta: Penerbit CV Alfabeta.

Sule, E.T., dkk. 2005. Pengantar Manajemen. Jakarta: Penerbit Kencana Prenada Media Group.

Tim Dirjen Bimas Islam. 2007. Pedoman Pengelolaan Wakaf Tunai. Jakarta: Penerbit Direktorat Pemberdayaan Wakaf. . 2007. Paradigma Baru Wakaf di Indonesia. Jakarta: Penerbit Direktorat Pemberdayaan Wakaf.

. 2007. Strategi Pengembangan Wakaf Tunai di Indonesia. Jakarta: Penerbit Direktorat Pemberdayaan Wakaf.

Usman, S. 1994. Hukum Perwakafan di Indonesia. Jakarta: Penerbit Darul Ulum Press.

Wadjdy, F., dan Mursyid. 2007. Wakaf dan Kesejahteraan Umat: Filantropi Islam yang Hampir Terlupakan. Yogyakarta: Penerbit Pustaka Pelajar.

Widjajakusuma, M.K., dan M. Ismail, Y. 2002. Pengantar Manajemen Syariat. Jakarta: Penerbit Khairul Bayan. http://www.kompasiana.com)/welcome diakses pada tanggal 19 Mei 2010 pukul 06.45 wib). 